\title{
Role of customised negative-pressure wound therapy in the integration of split-thickness skin grafts: A randomised control study
}

\author{
Mir Mohsin, Haroon Rashid Zargar, Adil Hafeez Wani, Mohammad Inam Zaroo, \\ Peerzada Umar Farooq Baba, Sheikh Adil Bashir, Altaf Rasool, Akram Hussain Bijli \\ Department of Plastic and Reconstructive Surgery, SKIMS, Srinagar, Jammu and Kashmir, India
}

Address for correspondence: Dr. Mir Mohsin, 150, Nursingarh, Srinagar - 190 010, Jammu and Kashmir, India.

E-mail: m_mohsin@rediffmail.com

\section{ABSTRACT}

Background: Split-thickness skin grafting (STSG) is a time-tested technique in wound cover, but many factors lead to suboptimal graft take. Role of custom-made negative-pressure wound therapy (NPWT) is compared with conventional dress in the integration of STSG and its cost is compared with widely used commercially available NPWT. Materials and Methods: This is a parallel group randomised control study. Block randomisation of 100 patients into one of the two groups (NPWT vs. non-NPWT; 50 patients each) was done. Graft take/loss, length of hospital stay post-grafting, need for regrafting and cost of custom-made negative pressure wound therapy (NPWT) dressings as compared to widely used commercially available NPWT were assessed. Results: Mean graft take in the NPWT group was $99.74 \% \pm 0.73 \%$ compared to $88.52 \% \pm 9.47 \%$ in the non-NPWT group $(P=0.004)$. None of the patients in the NPWT group required second coverage procedure as opposed to six cases in the non-NPWT group $(P=0.035)$. All the patients in the NPWT group were discharged within 4-9 days from the day of grafting. No major complication was encountered with the use of custom-made NPWT. Custom-made NPWT dressings were found to be 22 times cheaper than the widely used commercially available NPWT. Conclusions: Custom-made NPWT is a safe, simple and effective technique in the integration of STSG as compared to the conventional dressings. We have been able to reduce the financial burden on the patients as well as the hospital significantly while achieving results at par with other studies which have used commercially available NPWT.

\section{KEY WORDS}

Negative-pressure wound therapy; skin transplantation; wounds and injuries

\begin{tabular}{|l|l|}
\hline \multicolumn{2}{|c|}{ Access this article online } \\
\hline Quick Response Code: & Website: \\
\hline & www.ijps.org \\
\cline { 2 - 2 } & Dol: \\
\hline
\end{tabular}

This is an open access article distributed under the terms of the Creative Commons Attribution-NonCommercial-ShareAlike 3.0 License, which allows others to remix, tweak, and build upon the work non-commercially, as long as the author is credited and the new creations are licensed under the identical terms.

For reprints contact: reprints@medknow.com

How to cite this article: Mohsin M, Zargar HR, Wani AH, Zaroo MI, Baba PU, Bashir SA, et al. Role of customised negative-pressure wound therapy in the integration of split-thickness skin grafts: A randomised control study. Indian J Plast Surg 2017;50:43-9. 


\section{INTRODUCTION}

W

ounds requiring reconstruction are usually large with extensive soft-tissue loss caused by trauma, infections, burns, diabetic foot ulcers, pressure sores, etc. These situations often lead to considerable distress to the patients and have a negative impact on the physical, emotional, social and economic aspects of their lives. ${ }^{[1,2]}$

One of the principal tools of a reconstructive surgeon is the split-thickness skin graft (STSG), which is a simple yet versatile technique for reconstruction of cutaneous defects. The major causes of skin graft loss are the formation of blisters or hematomas under the graft which interfere directly with serum imbibition and revascularisation, lack of proper apposition of graft to its bed and infection of the graft. Thus, further interventions are required for successful coverage of such wounds. ${ }^{[3]}$

The efficacy of negative-pressure wound therapy (NPWT) in wound care was initially described by Morykwas et al..$^{[4]}$ in the United States in 1997. It has also been used to optimally prepare the wound surface for graft acceptance and to enhance graft take. ${ }^{[5-7]}$

Commercially available NPWT has become popular, but despite its presence in the market for two decades, the main reason for its limited usage is its cost, and alternatives have been keenly sought. ${ }^{[8]}$ Patients who attend to our hospital belong to low socioeconomic strata as such they cannot afford the cost of commercially available NPWT dressing. However, we wanted to provide our patients the benefit of this new wound care concept as such we devised a custom-made NPWT.

\section{Objectives}

- To determine its feasibility and safety

- Whether custom-made NPWT improves the skin graft take

- Whether custom-made NPWT shortens hospital stay

- Need for secondary wound coverage procedures

- Cost-effectiveness.

\section{MATERIALS AND METHODS}

This was a parallel group randomised control study conducted from January 2013 to December 2015 in our department. The research was conducted according to the principles of the Declaration of Helsinki after obtaining clearance from the Institution's Ethical Committee.

A total sample size of 100 patients was considered to be sufficient to detect a difference of $10 \%$ in graft take between the two groups with a power of $90 \%$ with $95 \%$ confidence. After informed consent, all the enrolled 100 patients with wounds ready to be grafted due to varied aetiologies were subjected to detailed history, systemic and local examination followed by routine investigations and wound swab cultures. Patients aged below 10 years, ones with psychiatric disorders and those who refused consent were excluded from the study [Supplementary Figure 1].

The wounds were prepared by debridement, serial saline/betadine dressing or by NPWT until fit for grafting [Figure 1a]. STSG of intermediate thickness was harvested, fenestrated and sutured to the recipient site. Once the graft was fixed, block randomisation of the patient into one of the two groups (NPWT vs. non-NPWT; 50 patients each) was done by computer-generated numbers. Allocation concealment was done by sealed envelope method.

\section{Negative-pressure wound therapy group}

The STSG was covered with a single layer of paraffin gauze dressing, followed by two sheets of autoclave sterilised locally available open cell polyurethane foam (cut to fit the contour of the wound) with a fenestrated tube between the two layers and covered with a transparent adhesive dressing (iodrape) creating a vacuum seal after bringing the tube out through a hole made in the adhesive dressing and securing the tube to the opening with iodrape pieces [Figure 2a]. While applying customised NPWT on hairy areas such as head and neck, groin and sacrum, hair was shaved/trimmed for $3-5 \mathrm{~cm}$ around the wound for adequate seal with

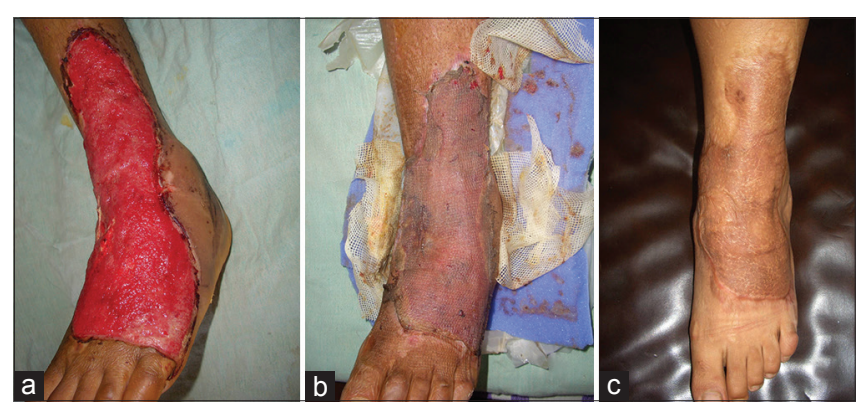

Figure 1: (a) Healthy granulating wound, (b) complete graft take on the $4^{\text {th }}$ post-operative day while removing the negative-pressure wound therapy dressing, (c) stable graft at follow-up 
iodrape. Besides, prior tincture benzoin application helps in better adherence of iodrape in these areas. No differences exist in application of customised NPWT over limbs as compared to flat surfaces such as trunk. The patient was transported to the recovery room and back to the ward. After arrival in the ward, before connecting the tubing to the wall mounted suction [Figure 2b], vacuum regulator was adjusted to the desired negative pressure level $(125 \mathrm{mmHg})$ by occluding the outlet of the canister with the thumb. After connecting the tubing to the canister, further titration of pressure was done if required. The tubing has to be of sufficient wall thickness so that it does not collapse when exposed to high negative pressures and some bending.

\section{Non-negative-pressure wound therapy group}

The STSG was covered with a single layer of paraffin gauze dressing, followed by tie over bolster dressing. Supplementary Plaster of Paris slab was used in extremity wounds.

\section{Post-operative care}

After the intervention, patients were confined to bed and allowed limited movement only for personal hygiene. Patients in the NPWT group were kept on continuous suction for 4 days. No extended wound care was performed in both the groups until $4^{\text {th }}$ post-operative day when all wounds were uncovered and assessed and photographs were taken [Figure 1b and c]. NPWT was not applied again after $4^{\text {th }}$ post-operative day in any case.

\section{Outcome}

The main outcome was the percentage and the area in $\mathrm{cm}^{2}$ of skin graft take and graft loss. It was assessed with the help of digital photographs which were taken from a

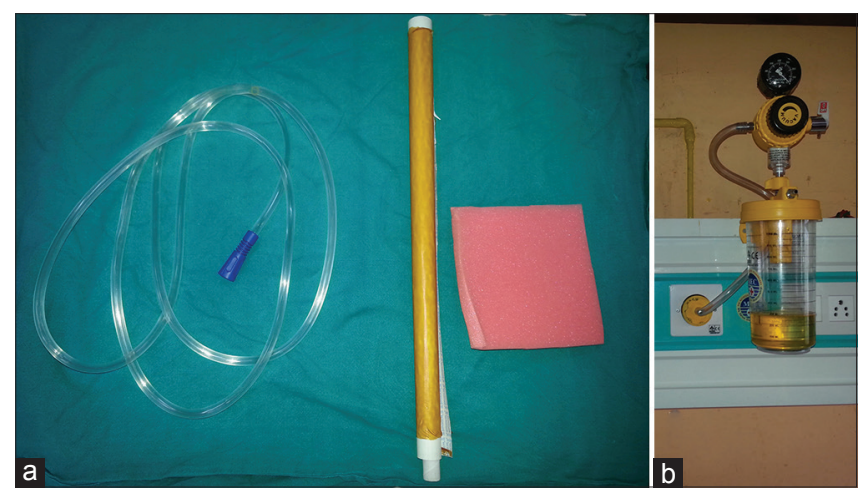

Figure 2: (a) Locally available disposables used for customised negative-pressure wound therapy: Polyurethane foam, iodrape and tubing,

(b) Wall mounted canister connected to hospital central suction distance of $40 \mathrm{~cm}$ from the wound with a single camera and analysed with the Adobe $\mathrm{CS}_{3}$ software by a third person who was blinded to group allocation.

Other outcomes that were assessed are:

- Length of hospital stay after grafting

- Requirement for regrafting the same site

- Cost of custom-made NPWT dressings as compared to widely used commercially available NPWT.

\section{Statistical analysis}

Data were analysed using SPSS for Windows IBM Corp., Released 2011. IBM SPSS statistics for Windows, version 20.0. IBM Corp., Armonk, NY, USA. Categorical outcomes in the two groups were compared using Yates-corrected Chi-square test. Continuous outcome measures were compared using Mann-Whitney U-test. All $P$ values were two-sided, and a $P<0.05$ was considered statistically significant.

\section{RESULTS}

Baseline demographics of the patients are shown in Table 1. Trauma was the leading cause of wounds, and ankle and foot was the most common site (52.83\%) in both the groups [Table 1]. Around one-third of the

Table 1: Demographics of the patients, aetiology and distribution of wounds

\begin{tabular}{lcc} 
Variable & $\begin{array}{c}\text { NPWT group } \\
(\boldsymbol{n}=50)\end{array}$ & $\begin{array}{c}\text { Non-NPWT } \\
\text { group }(\boldsymbol{n}=50)\end{array}$ \\
\hline Age (mean $\pm S D)$ & $39.5 \pm 16.2$ & $40.1 \pm 17.4$ \\
Sex & & \\
Male & 36 & 39 \\
Female & 14 & 11 \\
Cause of wound (\%) & & \\
Trauma & $28(56)$ & $26(52)$ \\
Diabetes & $10(20)$ & $7(14)$ \\
Burn & $6(12)$ & $8(16)$ \\
Post-fasciotomy & $2(4)$ & $3(6)$ \\
Post-infective & $3(6)$ & $3(6)$ \\
Frostbite & $1(2)$ & $3(6)$ \\
Site of wound (\%) & & - \\
Scalp & $2(3.7)$ & $2(3.8)$ \\
Neck & - & $2(3.8)$ \\
Chest & - & $2(3.8)$ \\
Upper limbs & $6(11.1)$ & $14(26.9)$ \\
Thigh & $2(3.7)$ & $12(23)$ \\
Leg & $8(14.8)$ & $20(38.5)$ \\
Ankle and foot & $36(66.6)$ & $52(100)$ \\
Total number of wounds & $54(100)$ & \\
\hline Four patients in the NPT group and two patients in the non-NPT group had two \\
wounds each, while rest of the patients had one wound each. SD: Standard \\
deviation, NPWT: Negative pressure wound therapy
\end{tabular}


wounds in both the groups (36 [33.96\%]) were prepared for STSG by NPWT pre-operatively while conventional betadine-saline dressing was used in the remaining wounds. Area and percentage of graft take/loss was calculated after assessment of wounds on the $4^{\text {th }}$ post-operative day [Table 2]. The mean difference in the percentage of graft take was $11.22 \%$ with $95 \%$ confidence interval of 5.75-16.69.

None of the patients in the NPWT group required second coverage procedure as opposed to six cases in the non-NPWT group who had to undergo second-stage grafting for adequate wound cover $(P=0.035)$.

All the patients in the NPWT group were discharged within 4-9 days from the day of grafting. In the non-NPWT group, $40 \%$ cases had to stay beyond 9 days, and the maximum duration of hospital stay post-grafting was 22 days.

No major complication was encountered with the use of custom-made NPWT. Minor complications included maceration in six patients and pain on the removal of NPWT in nine patients which was managed by thorough cleaning, analgesics and infiltration of xylocaine through tubing 10 min before dressing change.

For analysing cost of dressing using handcrafted as compared to commercially available dressing, wounds were divided into three groups depending on the maximum dimensions of the wound [Table 3].

\section{DISCUSSION}

In a short span of 20 years, since NPWT has come into vogue, it has been used for the integration of STSG for wounds of varied aetiologies. More than half of the wounds in both the groups of our study were caused by trauma (28 cases [56\%] in the NPWT group and 26 cases [52\%] in the non-NPWT group). Diabetes (10 cases [20\%]) and burns (8 cases [16\%]) were the second leading causes of wounds in NPWT and non-NPWT groups, respectively. Trauma was the leading cause of wounds in the series presented by Moisidis et $a .^{[9]}$ and Jeschke et al. ${ }^{[10]}$ as seen in our study while Llanos et al. ${ }^{[3]}$ Scherer et al. ${ }^{[11]}$ and Kamolz et al. ${ }^{[12]}$ reported the use of NPWT over graft mostly in burns.

Other causes of wounds reported in literature for which NPWT has been used for the integration of STSG include diabetic wounds, ${ }^{[13]}$ hidradenitis cystica and amputation stump wounds, ${ }^{[5]}$ wounds following excision of irradiated extremity sarcomas, ${ }^{[14]}$ necrotising fasciitis and associated pubic bone osteomyelitis, ${ }^{[15]}$ Fournier's gangrene, ${ }^{[16]}$ chronic leg ulcers, ${ }^{[17]}$ over punch grafts after excision of melanoma feet ${ }^{[18]}$ and over radial forearm free flap donor sites. ${ }^{[19]}$ NPWT has also been used for securing skin grafts to microvascular free flaps ${ }^{[20]}$ and for the vulvovaginal reconstruction with skin grafts. ${ }^{[21]}$ Role of NPWT has also been reported in single-stage approach to stabilise skin grafts on the skull after outer table bone was removed. ${ }^{.22]}$

Table 2: Mean area of wound, mean graft take and loss among the two groups

\begin{tabular}{|c|c|c|c|}
\hline \multirow[t]{2}{*}{ Variable } & \multicolumn{2}{|c|}{ Mean士SD } & \multirow[t]{2}{*}{$P$} \\
\hline & NPWT group* & Non-NPWT group* & \\
\hline Area of wound grafted $\left(\mathrm{cm}^{2}\right)$ & $93.78 \pm 74.12(12.62-327.40)$ & $135.68 \pm 122.82(17.34-516.65)$ & 0.137 \\
\hline Graft take (\%) & $99.74 \pm 0.73(96.60-100.00)$ & $88.52 \pm 19.47(13.40-100.00)$ & 0.004 \\
\hline Graft loss (\%) & $0.26 \pm 0.73(0.00-3.40)$ & $11.47 \pm 19.47(0.00-86.60)$ & 0.004 \\
\hline
\end{tabular}

Table 3: Cost difference between custom-made negative-pressure wound therapy dressings and widely used commercially available negative-pressure wound therapy dressings

\begin{tabular}{llccccc}
\hline $\begin{array}{l}\text { Serial } \\
\text { number }\end{array}$ & Size of dressing/wound & $\begin{array}{c}\text { Total number } \\
\text { of dressings } \\
\text { used }\end{array}$ & $\begin{array}{c}\text { Cost of single } \\
\text { commercial NPWT } \\
\text { dressing* (INR) }\end{array}$ & $\begin{array}{c}\text { Total cost of } \\
\text { commercial NPWT } \\
\text { dressings (INR) }\end{array}$ & $\begin{array}{c}\text { Cost of single } \\
\text { custom-made NPWT } \\
\text { dressing ** (INR) }\end{array}$ & $\begin{array}{c}\text { Total cost of } \\
\text { custom-made NPWT } \\
\text { dressings (INR) }\end{array}$ \\
\hline 1 & Small $(10 \mathrm{~cm} \times 7.5 \mathrm{~cm})$ & 36 & 7563 & 272,268 & 336 & 12,096 \\
2 & Medium $(18 \mathrm{~cm} \times 12.5 \mathrm{~cm})$ & 44 & 9075 & 399,300 & 385 & 16,940 \\
3 & Large $(26 \mathrm{~cm} \times 15 \mathrm{~cm})$ & 29 & 11,440 & 331,760 & 540 & 15,660 \\
Total & & & & $1,003,328$ & 44,696 \\
\hline
\end{tabular}

*MRP of widely used commercially available NPWT dressings in Jammu and Kashmir. The cost includes adhesive draping, polyurethane foam and connecting tube, ${ }^{* *}$ Cost of custom-made NPWT dressing. The cost includes adhesive draping (incise drape/iodrape), locally available half inch thick medium density open cell polyurethane foam with pore size of $400-600 \mu$ available as $6 \times 3$ feet sheet cut to desired size and autoclaved and connecting tubing. NPWT: Negative-pressure wound therapy, INR: Indian Rupee, MRP: Mediscor Reference Price 
Wounds are generally irregular in shape, so the calculation of wound size becomes a difficult task. We used the tracing of the wound (initial and final stage). This tracing along with a scale was photographed, and the wound area and area of graft take and graft loss were calculated using computer software Adobe Photoshop CS3. Llanos et al. ${ }^{[3]}$ used AutoCAD software for calculation of wound size, whereas Mouës et al..$^{[1]}$ used Adobe Photoshop for same purpose.

Both the groups were comparable with no statistically significant difference $(P=0.137)$ as far as the size of wound was concerned. NPWT has been used over STSG for the coverage of wounds ranging from small to large sizes. The mean wound sizes of the two groups of our study were $93.78 \pm 74.12 \mathrm{~cm}^{2}$ in NPWT and $135.68 \pm 122.82 \mathrm{~cm}^{2}$ in non-NPWT groups, respectively. Many studies have reported similar mean wound size as ours ${ }^{[14]}$ while some have reported smaller ${ }^{[3,23]}$ and larger ${ }^{[10,11,22]}$ wounds.

Non-standard/custom-made NPWT has been used over STSG by Llanos et al., ${ }^{[3]}$ Petkar et al..$^{[24]}$ and Dorafshar et al. ${ }^{[25]}$ with comparable results.

\section{Assessment of post-operative graft take/graft loss (area and percentage)}

Mean graft take in the NPWT group was $99.74 \% \pm 0.73 \%$ compared to $88.52 \% \pm 9.47 \%$ in the non-NPWT group, difference was statistically significant $(P=0.004)$. Mean graft loss in the NPWT group was $0.26 \% \pm 0.73 \%$ compared to $11.47 \% \pm 19.47 \%$ in the non-NPWT group which also turned out to be statistically significant $(P=0.004)$.

Several studies have reported statistically significant difference in the quality and quantity of graft take using NPWT over graft as compared to conventional dressing, similar to our results. ${ }^{[3,6,9-12,24-27]}$ Furthermore, significant difference in the mean graft loss between the two groups has been reported by Llanos et al. ${ }^{[3]}$ concordant to our results.

Several postulates suggest why negative pressure dressings may improve graft survival. ${ }^{[4]}$ First, an important aspect to successful graft take is maintaining good apposition between the graft and the wound surface. By design, continuous negative pressure dressings provide a uniform distribution of negative pressure and apposition between the graft and the wound bed in most cases, even if the surface contour is irregular. ${ }^{[22,28]}$ This becomes particularly important for patients with traumatic injuries necessitating skin grafting as these grafts are often in irregularly contoured regions such as the hand, wrist and ankle. Second, accumulation of hematoma or seroma under the graft contributes to graft loss. The negative pressure dressing provides continuous removal of wound fluid, which prevents the accumulation of hematoma or seroma while maintaining graft to wound apposition. ${ }^{[5,28]}$ Third, desiccation is detrimental to wound healing ${ }^{[29]}$ and is reduced with the occlusive nature of the NPWT dressing, in which a moist environment is maintained. Last, infection contributes to graft loss. NPWT has been associated with lower bacterial counts at wound sites, ${ }^{[4]}$ and this reduction in the local bacterial flora may enhance graft survival.

\section{Need for second-stage grafting}

None of the patients in the NPWT group required second coverage procedure as opposed to six cases in the non-NPWT group who had to undergo second-stage STSG for adequate wound coverage which is a statistically significant difference $(P<0.05)$.

Initial graft survival with NPWT reduces the need for repeated grafting, which may eliminate costly repeated surgical expense and hospital stay. ${ }^{[6]}$ Many studies have reported significant reduction in the reoperation rates in the grafts covered by NPWT as found in our study ${ }^{[3,6,11]}$ while Moisidis et al. ${ }^{[9]}$ reported no need for regrafting any case in either of the two groups. Home-made devices are more effective at preventing reoperation, and patients report less pain on dressing change..$^{[30]}$

\section{Hospital stay in days from grafting to discharge}

Expediting the patients discharge to home offers a cost-effective advantage to both hospital and patient. In our study, all the patients in the NPWT group were discharged within 4-9 days from the day of grafting. In the non-NPWT group, 10 cases $(40 \%)$ had to stay beyond 9 days, and the maximum duration of post-grafting hospital stay was 22 days. Length of post-STSG hospital stay was significantly reduced in the NPWT group $(P=0.034)$, thus reducing the burden on the hospital workforce, resources and infrastructure and enabling their better utilisation.

Llanos et al. ${ }^{[3]}$ noted that the mean post-grafting hospital stay was 8 days (range 7-13 days) in the negative pressure group versus 12 days (7-23 days) in the control group which was statistically significant $(P=0.001)$ and is in agreement with our study. Scherer et al. ${ }^{[11]}$ noted that the 
post-STSG length of hospital stay was $14 \pm 10$ days in the NPWT group compared to $19 \pm 15$ days in the non-NPWT group which was not significant.

No major complications were encountered in our study with the use of custom-made NPWT. Safety of home-made NPWT has been reported by many studies. ${ }^{[3,24,25]}$

\section{Cost}

The cost of custom-made NPWT which was used in our study was around 22 times cheaper than the widely used commercially available NPWT.

Cost of home-made vacuum dressing for an average-sized wound was INR 448 per dressing in the study conducted by Petkar et al. ${ }^{[2]}$ almost same as our custom-made medium-sized dressing. Dorafshar et al. ${ }^{[25]}$ reported that the combined equipment and labour costs were four times lower when a hospital devised and built system was used than when a commercial system was used for delivery of NPWT (USD 25.4/day compared to 110.6/day). The cost of equipment used for one indigenously crafted dressing reported by Andreassen and Madsen ${ }^{[31]}(16 €)$ is 10 times cheaper than the commercial method. Rozen et al. ${ }^{26]}$ reported cost of dressing as $\$ 557$ over 5 days compared to $\$ 3180$ for commercial counterpart (5-6 times more) with net saving of $\$ 2603$ per patient.

There are definite advantages of the commercially available NPWT dressing such as no need to assemble the dressing material, good negative pressure regulation, effluent management is better and the patient can be ambulatory. However, for optimal utilisation of NPWT in wound care, its affordability is a very important factor, especially in developing countries.

\section{CONCLUSIONS}

Custom-made NPWT is a safe, useful, simple and effective technique in the integration of STSG as compared to the conventional dressing. It decreases the need for secondary wound coverage procedures and leads to a reduction of the days of hospital stay with all the benefits to the patient and the hospital. We have been able to reduce the financial burden on the patients as well as the hospital significantly while achieving results at par with other studies which have used commercially available NPWT. More of such cost-effective methods and studies are required to provide the benefit of NPWT to underprivileged poor patients of developing countries as the cost of the widely used commercially available NPWT makes its use restricted to only those who can afford its huge cost.

\section{Acknowledgements}

We acknowledge the guidance and support provided by the Ex Head of Our Department Prof. M. A. Darzi in conducting this study and statistical help by Dr. Inam-ul Haq Assistant Professor in the Department of Preventive and Social Medicine, GMC, Srinagar.

\section{Financial support and sponsorship}

Nil.

\section{Conflicts of interest}

There are no conflicts of interest.

\section{REFERENCES}

1. Mouës CM, van den Bemd GJ, Heule F, Hovius SE. Comparing conventional gauze therapy to vacuum-assisted closure wound therapy: A prospective randomised trial. J Plast Reconstr Aesthet Surg 2007;60:672-81.

2. Andersson AE, Bergh I, Karlsson J, Nilsson K. Patients' experiences of acquiring a deep surgical site infection: An interview study. Am J Infect Control 2010;38:711-7.

3. Llanos S, Danilla S, Barraza C, Armijo E, Piñeros JL, Quintas M, et al. Effectiveness of negative pressure closure in the integration of split thickness skin grafts: A randomized, double-masked, controlled trial. Ann Surg 2006;244:700-5.

4. Morykwas MJ, Argenta LC, Shelton-Brown El, McGuirt W. Vacuum-assisted closure: A new method for wound control and treatment: Animal studies and basic foundation. Ann Plast Surg 1997;38:553-62.

5. Blackburn JH $2^{\text {nd }}$, Boemi L, Hall WW, Jeffords K, Hauck RM, Banducci DR, et al. Negative-pressure dressings as a bolster for skin grafts. Ann Plast Surg 1998;40:453-7.

6. Blume PA, Key JJ, Thakor P, Thakor S, Sumpio B. Retrospective evaluation of clinical outcomes in subjects with split-thickness skin graft: Comparing V.A.C. ${ }^{\circledR}$ therapy and conventional therapy in foot and ankle reconstructive surgeries. Int Wound J 2010;7:480-7.

7. Gupta S. Optimal use of negative pressure wound therapy for skin grafts. Int Wound J 2012;9 Suppl 1:40-7.

8. Hussain A, Singh K, Singh M. Cost effectiveness of vacuum - Assisted closure and its modifications: A review. ISRN Plast Surg 2013;2013:595789.

9. Moisidis E, Heath T, Boorer C, Ho K, Deva AK. A prospective, blinded, randomized, controlled clinical trial of topical negative pressure use in skin grafting. Plast Reconstr Surg 2004;114:917-22.

10. Jeschke MG, Rose C, Angele P, Füchtmeier B, Nerlich MN, Bolder U. Development of new reconstructive techniques: Use of Integra in combination with fibrin glue and negative-pressure therapy for reconstruction of acute and chronic wounds. Plast Reconstr Surg 2004;113:525-30.

11. Scherer LA, Shiver S, Chang M, Meredith JW, Owings JT. The vacuum assisted closure device: A method of securing skin grafts and improving graft survival. Arch Surg 2002;137:930-3. 
12. Kamolz LP, Lumenta DB, Parvizi D, Wiedner M, Justich I, Keck M, et al. Skin graft fixation in severe burns: Use of topical negative pressure. Ann Burns Fire Disasters 2014;27:141-5.

13. Ferreira MC, Carvalho VF, Kamamoto F, Tuma P Jr., Paggiaro AO. Negative pressure therapy (vacuum) for wound bed preparation among diabetic patients: Case series. Sao Paulo Med J 2009;127:166-70.

14. Senchenkov A, Petty PM, Knoetgen J $3^{\text {rd }}$, Moran SL, Johnson CH, Clay RP. Outcomes of skin graft reconstructions with the use of Vacuum Assisted Closure (VAC (R)) dressing for irradiated extremity sarcoma defects. World J Surg Oncol 2007;5:138.

15. Kumar S, O’Donnell ME, Khan K, Dunne G, Carey PD, Lee J. Successful treatment of perineal necrotising fasciitis and associated pubic bone osteomyelitis with the vacuum assisted closure system. World J Surg Oncol 2008;6:67.

16. Weinfeld AB, Kelley P, Yuksel E, Tiwari P, Hsu P, Choo J, et al. Circumferential negative-pressure dressing (VAC) to bolster skin grafts in the reconstruction of the penile shaft and scrotum. Ann Plast Surg 2005;54:178-83.

17. Körber A, Franckson T, Grabbe S, Dissemond J. Vacuum assisted closure device improves the take of mesh grafts in chronic leg ulcer patients. Dermatology 2008;216:250-6.

18. Seo J, Kim J, Nam KA, Zheng Z, Oh BH, Chung KY, et al. Reconstruction of large wounds using a combination of negative pressure wound therapy and punch grafting after excision of acral lentiginous melanoma on the foot. J Dermatol 2016;43:79-84.

19. Andrews BT, Smith RB, Chang KE, Scharpf J, Goldstein DP, Funk GF. Management of the radial forearm free flap donor site with the Vacuum-Assisted Closure (VAC) system. Laryngoscope 2006;116:1918-22.

20. Hanasono MM, Skoracki RJ. Securing skin grafts to microvascular free flaps using the Vacuum-Assisted Closure (VAC) device. Ann Plast Surg 2007;58:573-6.

21. Dainty LA, Bosco JJ, McBroom JW, Winter WE $3^{\text {rd }}$, Rose GS, Elkas JC. Novel techniques to improve split-thickness skin graft viability during vulvo-vaginal reconstruction. Gynecol Oncol 2005;97:949-52.
22. Molnar JA, DeFranzo AJ, Marks MW. Single-stage approach to skin grafting the exposed skull. Plast Reconstr Surg 2000;105:174-7.

23. Repta R, Ford R, Hoberman L, Rechner B. The use of negative-pressure therapy and skin grafting in the treatment of soft-tissue defects over the Achilles tendon. Ann Plast Surg 2005;55:367-70.

24. Petkar KS, Dhanraj P, Kingsly PM, Sreekar H, Lakshmanarao A, Lamba $\mathrm{S}$, et al. A prospective randomized controlled trial comparing negative pressure dressing and conventional dressing methods on split-thickness skin grafts in burned patients. Burns 2011;37:925-9.

25. Dorafshar AH, Franczyk M, Gottlieb LJ, Wroblewski KE, Lohman RF. A prospective randomized trial comparing subatmospheric wound therapy with a sealed gauze dressing and the standard vacuum-assisted closure device. Ann Plast Surg 2012;69:79-84.

26. Rozen WM, Shahbaz S, Morsi A. An improved alternative to Vacuum-Assisted Closure (VAC) as a negative pressure dressing in lower limb split skin grafting: A clinical trial. J Plast Reconstr Aesthet Surg 2008;61:334-7.

27. Azzopardi EA, Boyce DE, Dickson WA, Azzopardi E, Laing JH, Whitaker IS, et al. Application of topical negative pressure (Vacuum-Assisted Closure) to split-thickness skin grafts: A structured evidence-based review. Ann Plast Surg 2013;70:23-9.

28. Argenta LC, Morykwas MJ. Vacuum-assisted closure: A new method for wound control and treatment: Clinical experience. Ann Plast Surg 1997;38:563-76.

29. Dyson M, Young SR, Hart J, Lynch JA, Lang S. Comparison of the effects of moist and dry conditions on the process of angiogenesis during dermal repair. J Invest Dermatol 1992;99:729-33.

30. Webster J, Scuffham P, Stankiewicz M, Chaboyer WP. Negative pressure wound therapy for skin grafts and surgical wounds healing by primary intention. Cochrane Database Syst Rev 2014; Oct 7;(10):CD009261.

31. Andreassen GS, Madsen JE. A simple and cheap method for vacuum-assisted wound closure. Acta Orthop 2006;77:820-4. 